\title{
Effect of metals on underwater adhesion of gastropod adhesive mucus
}

\section{Janu Newar, Suchanda Verma and Archana Ghatak*}

KIIT School of Biotechnology, Kalinga Institute of Industrial Technology (KIIT), Bhubaneswar751024, India

[*] Dr. A. Ghatak, Corresponding-Author, E-mail: aghatak@kiitbiotech.ac.in

\section{Supplementary Figure}

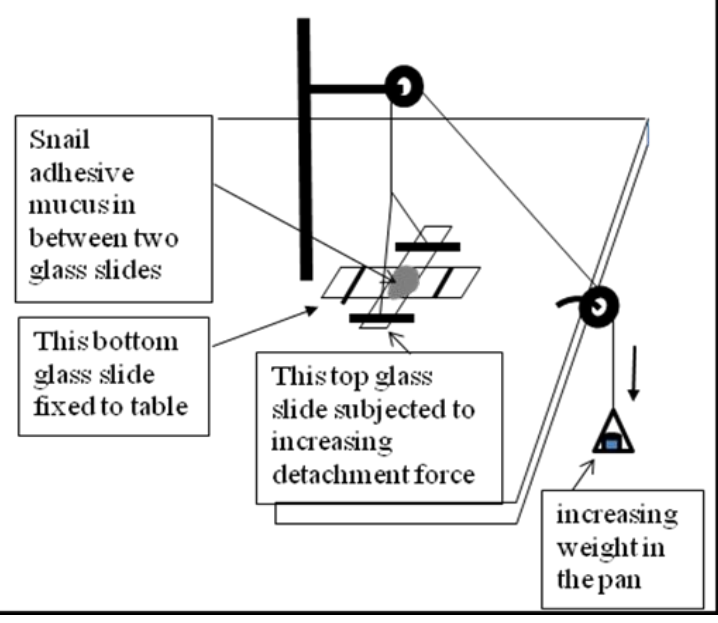

A

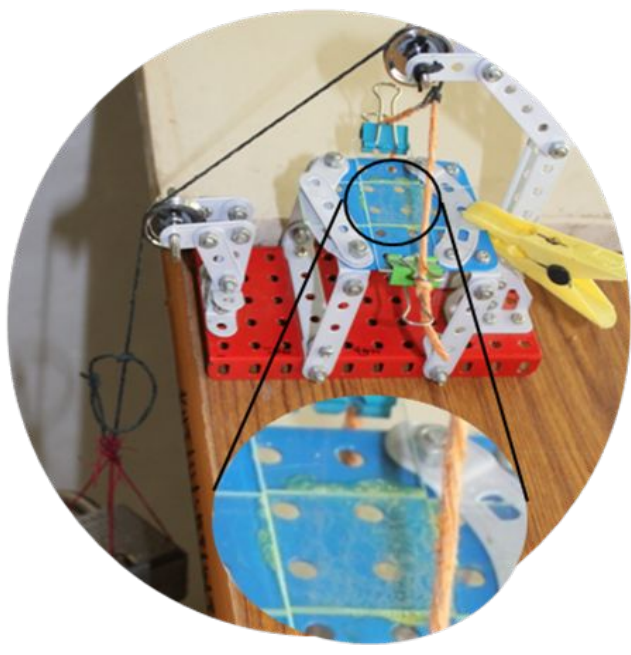

$\mathrm{B}$

Figure S1.

Measurement of adhesive property (Method 2) (A) Design of the instrument used to measure the force required to detach the slides that were attached with snail adhesive mucus. (B) An image of the instrument in the process of measuring adhesive force. (Inset) Snail mucus in between two glass slides.

(Reprinted from: Newar J, Ghatak A. Studies on the Adhesive Property of Snail Adhesive Mucus. Langmuir. 2015 Nov 10;31(44):12155-60. Copyright (C 2015 American Chemical Society) 